\title{
MICROSTRUCTURAL AND PHYSICAL ASPECTS OF HEAT TREATED WOOD. PART 2. HARDWOODS
}

M.J. Boonstra, J.F. Rijsdijk, C. Sander, E. Kegel,

B. Tjeerdsma, H. Militz, J. van Acker, M. Stevens

\begin{abstract}
Heat treatment of wood is an effective method to improve the dimensional stability and durability against biodegradation. Optimisation of a two-stage heat treatment process at relatively mild conditions $\left(<200^{\circ} \mathrm{C}\right)$ and its effect on the anatomical structure of hardwoods were investigated by means of a light and scanning electron microscopic analysis. Hardwood species such as beech and poplar, were predominantly sensitive to collaps of the vessels and some deformation of the libriform fibres directly near the vessels. In treated beech and birch radial cracks were observed near the rays. Optimisation of the heat treatment process conditions including the application of a steam hydro thermolysis stage reduced such damages to a minimum. Broken cell walls perpendicular to the fibre direction resulting in transverse ruptures has been noticed in heat treated hardwood species. This contributes to abrupt fractures of treated wood as observed in bending tests which can lead to considerably different failure behavior after impact of mechanical stress. In some treated hardwood species maceration (small cracks between tracheids) was noticed after heat treatment. Heat treatment did not reveal damage to the ray parenchyma pit membranes, bordered pits and large window pit membranes; and the margo fibrils appeared without damage.
\end{abstract}

Keywords. Wood modification, heat treatment, hardwood, microscopy.

\section{INTRODUCTION}

In the last decade several research groups have been developing industrial heat treatment methods to improve the dimensional stability and durability of wood (Viitaniemi and Jamsa, 1996; Weiland and Guyonnet, 1997; Boonstra et al, 1998). Beside these material improvements the timber quality after heat treatment is also of importance. During heat treatment wood defects such as cracking (internal and/ or surface cracks), collaps and deformation (e.g. bow, spring, twist and cup) might occur due to changes in the anatomical structure of wood (Boonstra et al, 2006). These defects are though to be caused by chemical and especially physical processes in wood during heat treatment.

In this paper the effect of a two-stage heat treatment process at relatively mild conditions $\left(<200^{\circ} \mathrm{C}\right)$ on the anatomical structure of hardwood is described. Heat treated hardwood specimens were investigated by means of light and scanning electron microscopy in order to reveal possible damages or changes of the wood structure. A description of the process development and its effect on the anatomical structure of softwoods has been reported in Part 1 (Boonstra et al, 2006).

Plato International BV, PO Box 2159, NL-6802 CD Arnhem, The Netherlands. M.Boonstra@ PlatoWood.nl.

${ }^{2}$ RINNTECH - Frank Rinn Engineering and Distribution. Bierhelder Weg 20, D-69126 Heidelberg, Germany

${ }^{3}$ SHR Hout Research, PO Box 497, 6700 AL Wageningen, The Netherlands

${ }^{4}$ Wood Biology and Wood Technology, University Göttingen, Büsgenweg 4, 37077 Göttingen, Germany

${ }^{5}$ Laboratory of Wood Technology, Ghent University, Coupure links 653, 9000 Ghent, Belgium

Corresponding author: M.Boonstra@PlatoWood.nl

Received: April 21, 2006

Accepted: September 28, 2006 


\section{MATERIALS AND METHODS}

The following timber species were used for heat treatment: European Beech (Fagus sylvatica L.), Poplar (Populus species, mainly Aspen, Robusta and I214), Simaruba (Simaruba amara AUBL.), Birch (Betula pendula/pubescens), Alder (Alnus glutinosa/incana), and Ash (Fraxinus excelsior L.). For each species at least 10 boards were treated per process condition. Cross sections of the boards had a thickness of $25-50 \mathrm{~mm}$ and a width of $100-150 \mathrm{~mm}$. The length of the boards/poles was approximately $3.0 \mathrm{~m}$. The moisture content of the boards/poles before treatment was varied, respectively fresh, water-soaked, shipping dry (16-20\%) or conditioned to a relatively low moisture content (12-14\%). Non-treated control specimens were used for comparison purposes.

The boards were treated according the two-stage heat treatment method as described in detail in Part 1 (Boonstra et al 2006). The methods used to analyse the wood structure of the boards, light microscopy and scanning electron microscopy, were also the same as reported in Part 1 (Boonstra et al, 2006).

\section{RESULTS AND DISCUSSION}

The first treatment stage (hydro thermolysis) is very critical to maintain the wood quality during further treatment (drying and curing) and therefore much attention has been focussed on the effect of this treatment stage on the anatomical structure of wood. The typical effects of the hydro thermolysis treatment on the anatomical wood structure during the process development are discussed below. Due to a large decrease of the visual wood quality (cracks, collaps and/or deformation) no light microscopic observations were made after the hydro thermolysis treatment of fresh (or pre-soaked) timber.

\section{Liquid full hydro thermolysis treatment of shipping dry hardwood}

During the liquid full hydro thermolysis treatment of shipping dry wood (18-22\% MC) the specimens absorbs water and the moisture content increases to values which could be far above the fibre saturation point (depending on the permeability of the wood species used). The occurrence of free water flowing into the cell lumens increases the possibility of collaps of wood cells, especially the vessels. Softening of the cell wall which occurs during the hydro thermolysis treatment further increases the possibility of collaps. In beech and poplar collaps was noticed after drying and even a slow and carefully controlled drying process did not prevent collaps of the vessels.

In figure 1a a strong collaps of the vessels and ray parenchyma cells of beech after the drying stage is visible. The parenchyma fibres between the libriform fibres with thick walls seemed not to be deformed. Radial cracks were observed close to large and broad rays. The ray parenchyma cells which were clean and open before treatment (in the non-treated wood), contained a brown-red extractive after hydro thermolysis treatment (Fig. 1b,c). This extractive is situated on the cell wall blocking the pits and preventing the transport of air and moisture through the pits in the radial direction. This probably caused a vacuum during the cooling down phase of the heat treatment resulting in collaps of vessels. The observed cracks could be the result of this collaps and/or a large difference in the tangential and radial shrinkage behaviour of the wood during heat treatment.

Unlike poplar and beech the liquid full hydro thermolysis treatment did not have an effect on the anatomical structure of simaruba, in which only some damage of the ray parenchyma cells has been observed. The anatomical structure and/or cell wall construction of simaruba is apparently strong enough to resist stresses during treatment. 


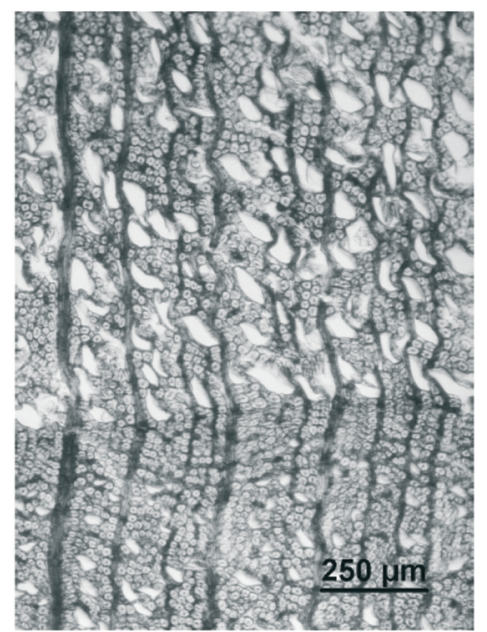

Fig. 1a Hydro thermolysed treated Beech (cross section), serious collaps of vessels
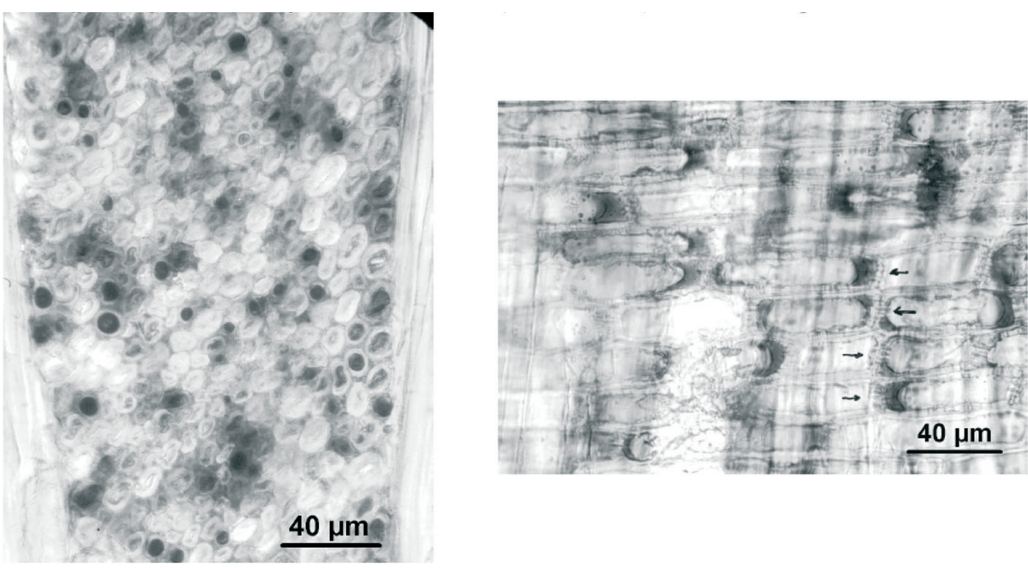

Fig. 1b+c Hydro thermolysed treated Beech (cross and tangential section), depletion of extractives on the cell wall

\section{Steam hydro thermolysis of shipping dry hardwood}

The application of a hydro thermolysis treatment with saturated steam resulted in a better (visual) wood quality than the liquid full hydro thermolysis treatment.

The first steam hydro thermolysis trials of poplar resulted in stresses in the wood specimens preventing the cutting of thin sections. Deformation of the fibres occurred and small cracks between the fibres were observed indicating maceration. A strong collaps was observed in the vessels, but also in the libriform fibres (Fig. 2a). The vessels collapsed at one side resulting in a deformation of the libriform fibres directly near the vessel. The occurrence of collaps was not common since in some specimens no collaps was observed. This might be related to the occurrence of tension wood. Optimisation of the steam hydro thermolysis treatment (conditioning of wood samples to a moisture content of 14-16\% before treatment, a careful and controlled heating and cooling down phase without abrupt temperature and pressure fluctuations, final treatment temperature and process time) prevented the occurrence of collaps of the vessels and no damages were observed after the drying stage (Fig. 2b). The existence of fibres on the 
surface of planed poplar in service conditions (due to weathering) indicates some maceration which could appear during or possibly after the treatment.

The phenomenon of transverse ruptures as discussed in Part 1 (Boonstra et al, 2006) was also observed in treated poplar. In the tangential cross section the tracheid cell walls were broken at several places perpendicular to the fibre direction (Fig. 3a,b). It is expected that the cause for this phenomenon could be related to the presence of tension wood. The fibres of tension wood exhibit a longitudinal shrinkage which is much larger compared to normal wood and the fibres are shorter compared to normal wood. Both of these factors might contribute to the abrupt fracture of treated poplar as observed in bending tests.

The first steam hydro thermolysis treatment trials of birch resulted in large radial cracks in the vicinity of the rays, and collaps of the vessels (Fig 4a). Optimisation of the treatment including a careful cooling down phase prevented the occurrence of radial cracks and collaps of the vessels (Fig 4b).

Bending tests which were performed on treated birch revealed in many occasions an abrupt fracture, especially for specimens which were sawn near the pith of the tree. This also indicates broken cell walls of the fibres perpendicular to the fibre direction resulting in transverse ruptures. The occurrence of juvenile wood with its typical characteristics (e.g. a shorter fibre length) could be the basic reason for this phenomenon.

An optimised steam hydro thermolysis treatment of alder which was carefully kiln dried to a moisture content of approximately $14 \%$ before treatment, revealed only slight collaps of the vessels and some damage to the fibres directly near the vessels (Fig. 5). No radial or tangential cracks were observed. Ash showed no damages after an optimised steam hydro thermolysis treatment, although it was expected that its characteristic ring-porous wood structure might cause some damage during treatment (Fig. 6).

Although some improvement was achieved after the application of steam hydro thermolysis, it was still difficult to treat beech without a serious loss of the (visual) wood quality. Even after optimisation of the hydro thermolysis stage, local occurrence of collaps, deformation and cracks in boards were still visible. This limits the application of treated beech in service conditions. Heat treatment of beech without the hydro thermolysis stage did not have an effect on the visual wood quality. This indicates that beech is very sensitive for damage to the wood structure during (or after) the hydro thermolysis treatment stage .

SEM analysis of heat treated beech did not reveal damage to the ray parenchyma pit membranes, bordered pits and large window pit membranes; and the margo fibrils appeared without damage. Kollmann and Sachs (1967) established a flow of the warty layer in beech, which they attributed to a plasticization of lignin. There was only a slight indication that this might also hold true for heat treated wood, leading to a deformation of the warty structures (Fig. 7a,b). Nevertheless, such type of changes were not distinct and it appears that plasticization of cell wall material has only a very limited effect during this heat treatment.

In simaruba, the differences of breaking behavior between fully treated wood specimen and nontreated control specimens were confirmed by SEM analysis. The fracture surface of heat treated simaruba appeared brittle and flat (Fig. 8a,b,c). Fractures in non-treated control specimens (Fig. 9a,b,c) lead to defibrillation of tissue and delamination of cell walls, resulting in a more axial orientation of detachments. In contrast to this, treated wood had straight fractures favoring detachments perpendicular to the longitudinal axis. 

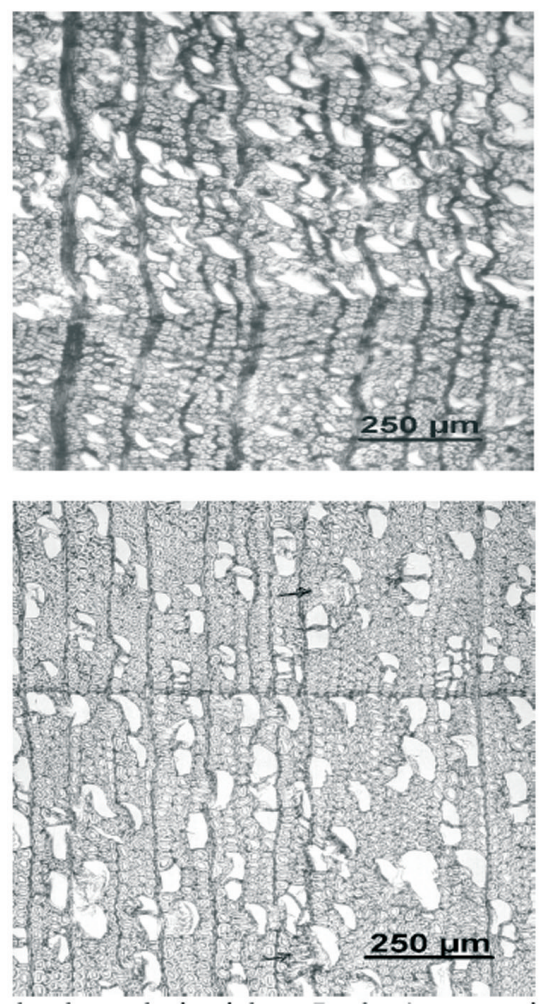

Fig. 2a First steam hydro thermolysis trials on Poplar (cross section), serious collaps of vessels

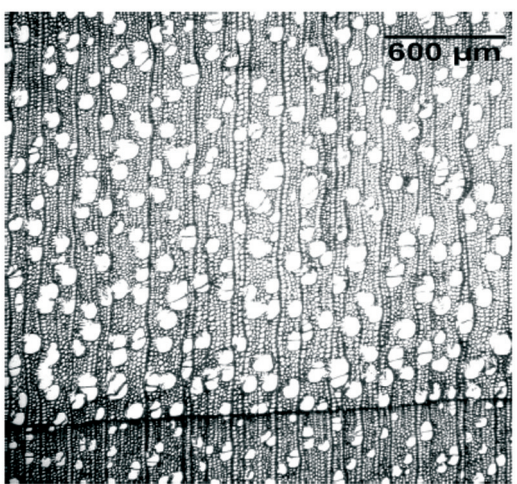

Fig. 2b Optimised steam hydro thermolysis of Poplar (cross section), without damages of the wood structure

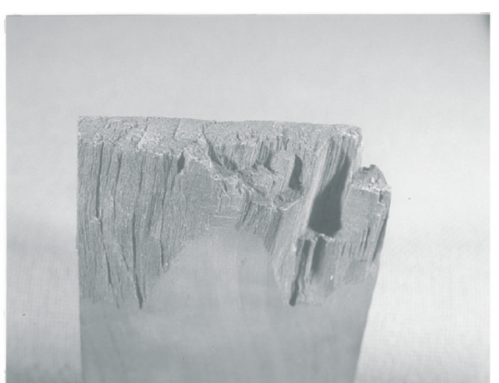

Fig. 3a The typical fracture of a completely treated Poplar specimen after a bending test 


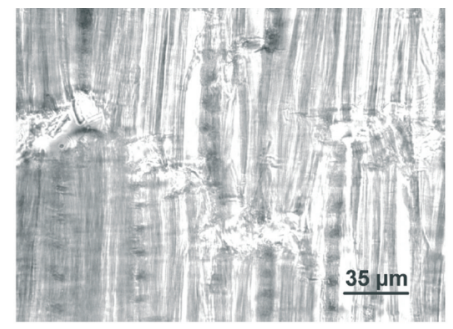

Fig. 3b Hydro thermolysed treated Poplar (cross and tangential section), broken tracheid cell walls perpendicular to the fibre direction

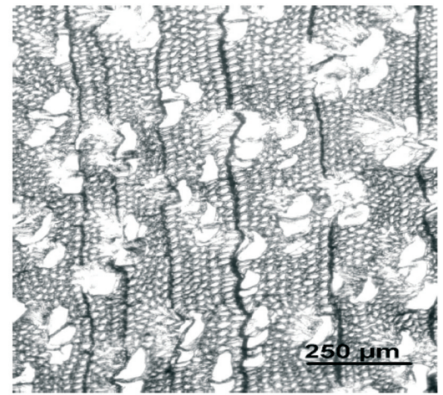

Fig. 4a First steam hydro thermolysis trials on Birch (cross section), radial cracks and collaps of the vessels

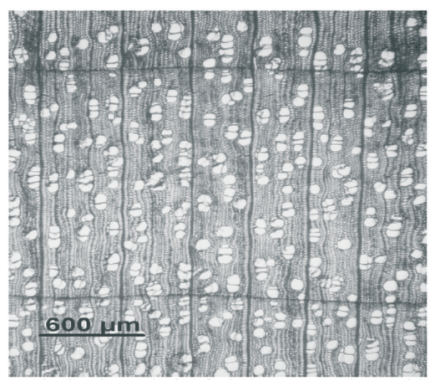

Fig. 4b Optimised steam hydro thermolysis of Birch (cross section), without damages of wood structure

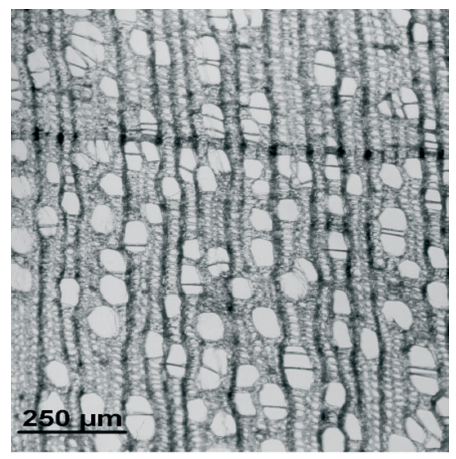

Fig. 5. Optimised steam hydro thermolysis of Alder (cross section), with a light collaps of the vessels and some damage directly near the vessels 


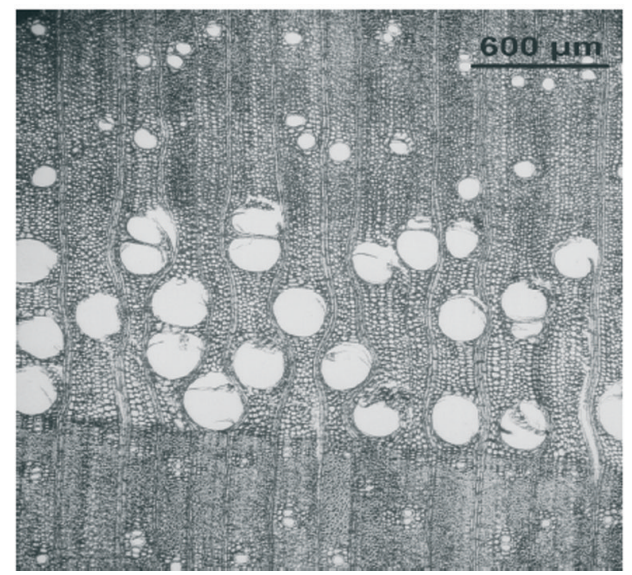

Fig. 6. Optimised steam hydro thermolysis of Ash (cross section), without damages of wood structure

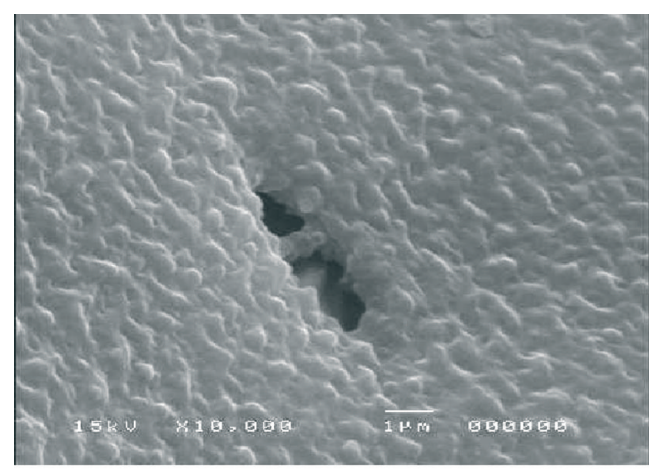

Fig. 7a Two stage heat treated Beech, warty layer around a vessel pit

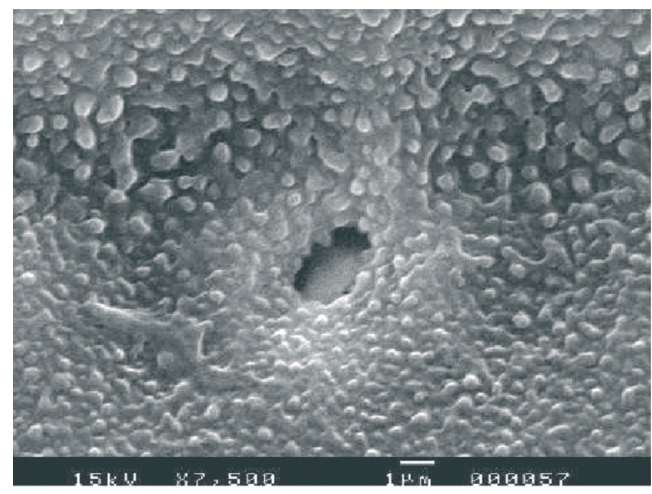

Fig. 7b Beech, non-untreated, warty layer around a vessel pit 

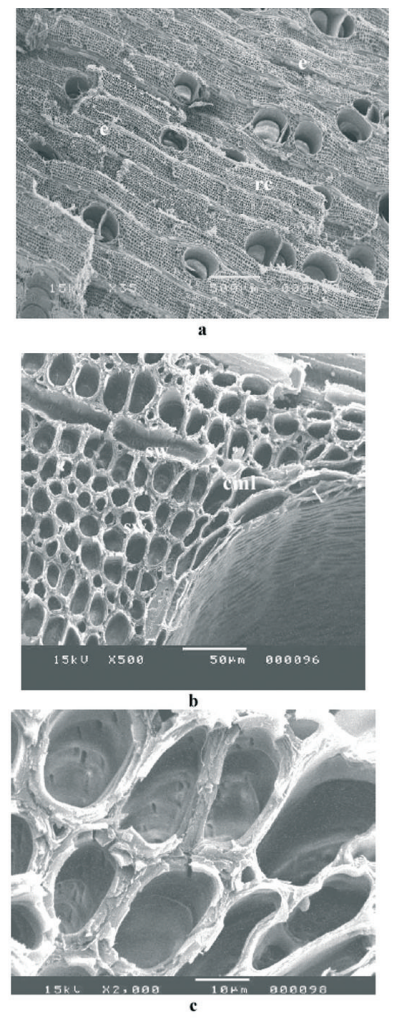

Fig. 8: Two stage heat treated Simarouba, fracture surface after bending test
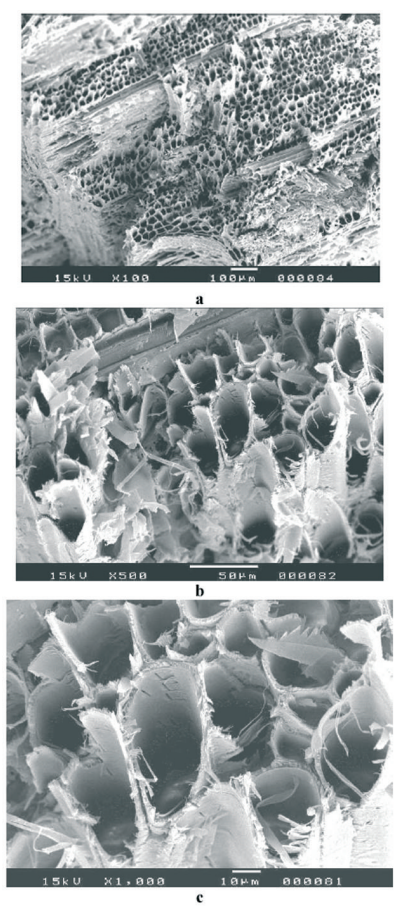

Fig. 9a-c Non-treated Simaruba, fracture surface after bending test. 


\section{CONCLUSIONS}

A two-stage heat treatment did reveal an effect on the anatomical structure of hardwood, depending on the wood species used and the process method or conditions applied. Hardwood species were predominantly sensitive to collaps of the vessels and some deformation of the libriform fibres directly near the vessels. In treated beech and birch radial cracks were observed near the rays. Optimisation of the heat treatment process conditions including the application of a steam hydro thermolysis stage reduced such damages to a minimum.

Broken cell walls perpendicular to the fibre direction resulting in transverse ruptures has been noticed in heat treated hardwood species. This contributes to abrupt fractures of treated wood as observed in bending tests which can lead to considerably different failure behavior after impact or mechanical stress. In some treated hardwood species maceration (small cracks between tracheids) was noticed after heat treatment. Heat treatment did not reveal damage to the ray parenchyma pit membranes, bordered pits and large window pit membranes; and the margo fibrils appeared without damage.

\section{Acknowledgements}

The authors are also very grateful that most of this research was financially supported by the Dutch government within the BTS program.

\section{REFERENCES}

Boonstra, M.J.; Tjeerdsma, B.F.; Groeneveld, H.A.C. 1998. Thermal modification of non-durable wood species. Part 1. The Plato technology: thermal modification of wood. International Research Group on Wood Preservation, Document no. IRG/WP 98-40123.

Boonstra, M.J.; Rijsdijk, J.F.; Sander, C.; Kegel, E.; Tjeerdsma, B.F.; Militz, M.; van Acker, J.; Stevens, M. 2006. Microstructural and physical aspect of heat treated wood Part 1. Softwoods. Maderas. Ciencia y tecnología 8 (3): 132-207

Bourgois, J.; Guyonnet, R. 1988. Characterization and analysis of torrified wood. Wood Science and Technology 22:143-155.

Kollmann, F.; Sachs, I.B. 1967. The effects of elevated temperature on certain wood cells. Wood Sci. Technol. 1: 14-25.

Viitaniemi, P.; Jamsa, S. 1996. Puun modifionti lampokassittelylla (Modification of wood with heat treatment). Espoo 1996, VTT Juskaisuja - Publikationer 814.

Weiland, J.J.; Guyonnet, R. 1997. Retifiziertes Holz. 16. Verdichter Holzbau in Europa. Motivation, Erfahrung, Entwicklung. Dreilander Holztagung. 10. Joanneum Research Fachtage. 2.-5.11.1997. Grazer Congress. Grazz. Austria 
